\title{
PENGARUH PENGGUNAAN LABEL HALAL DAN KUALITAS PRODUK TERHADAP KEPUTUSAN KONSUMEN UNTUK PEMBELIAN PIRANTI MASAK
}

\section{THE INFLUENCE OF THE USE OF HALAL LABELS AND PRODUCT QUALITY ON CONSUMER DECISIONS TO PURCHASE COOKWARE}

\author{
Aloysius Rangga Aditya Nalendra ${ }^{1)}$, Slamet Heri Winarno ${ }^{2)}$ \& Agus Priadi ${ }^{3)}$ \\ 1) Program Studi Manajemen Universitas Bina Sarana Informatika \\ 2) Program Studi Administrasi Perkantoran Universitas Bina Sarana Informatika \\ 3) Program Studi Bahasa Inggris Universitas Bina Sarana Informatika \\ Jalan Salemba Tengah No 22 Jakarta Pusat \\ rangga280@gmail.com, slamet.smh@bsi.ac.id,agus.agp@bsi.ac.id
}

\begin{abstract}
ABSTRAK
Program sertifikasi halal untuk berbagai jenis produk, baik makanan maupun nonmakanan, telah menjadi kebutuhan saat ini, sebagai bentuk tanggung jawab perusahaan dalam memasarkan produk yang aman untuk digunakan. Diyakini bahwa label halal pada setiap merek akan dapat menjadi faktor penentu bagi konsumen untuk membeli barang. Namun sejauh mana efektivitas hal tersebut, perlu dilakukan penelitian untuk membuktikannya. Penelitian ini bertujuan untuk mengetahui hubungan atau pengaruh pelabelan halal dan kualitas merek produk non pangan terhadap keputusan pembelian khususnya produk Teflon Maxim. Metode yang digunakan dalam penelitian ini adalah deskriptif kuantitatif dengan menggunakan teknik analisis korelasi yang menentukan tingkat hubungan dan pengaruh antar variabel. Hasil penelitian menunjukkan bahwa secara parsial variabel label halal (X1) dan kualitas produk (X2) berpengaruh signifikan terhadap keputusan pembelian, serta secara simultan kedua variabel tersebut berpengaruh signifikan terhadap keputusan pembelian, serta menjawab hipotesis yang diajukan.
\end{abstract}

Kata kunci: label halal, kualitas produk, keputusan pembelian.

\begin{abstract}
Halal certification programs for various types of products, both food and non-food, have become a necessity at this time, as a form of corporate responsibility in marketing products that are safe for use. It is believed that halal labeling on each brand will be able to be a determining factor for consumers to buy goods. However, to what extent is the effectiveness of this, it is necessary to research to prove it. This study aims to find the relationship or influence of halal labeling and the quality of non-food product brands on purchasing decisions, especially Teflon Maxim products. The method used in this research is descriptive quantitative using correlation analysis techniques that determine the level of relationship and influence between variables. The results showed that partially the halal label $\left(X_{1}\right)$ and product quality $\left(X_{2}\right)$ variables had a significant effect on purchasing decisions, as well as simultaneously the two variables showed a significant effect on purchasing decisions, as well as answering the proposed hypothesis.
\end{abstract}

Keywords: halal label, product quality, purchase decision. 


\section{SEGMEN Jurnal Manajemen dan Bisnis \\ Volume 17 No 2 Juli 2021 \\ p-ISSN: 0216-938X e-ISSN: 2684-8414}

\section{PENDAHULUAN}

Indonesia sebagai negara dengan jumlah penduduk mayoritas agama adalah pemeluk Islam menurut World Population Review memaparkan data jumlah penduduk muslim pada tahun 2020 mencapai 229 juta jiwa atau bisa dikatakan jumlah penduduk Muslim Indonesia sebesar 87,2\% dari total penduduk 273,5 juta jiwa. (Review, 2021). Hal ini mendominasi segala sector lini kehidupan tak terkecuali sektor ekonomi. Hasil dari Roadmap Industri Halal Indonesia memaparkan bahwa produk ekonomi halal nasional menyumbang Produk Domestik Bruto hingga US\$ 3,8 miliar per tahun sehingga dimungkinkan Indoneseia bisa menjadi mesin halal ekonomi global. Dengan kondisi tersebut, maka tak pelak kehalalan suatu produk menjadi prioritas konsumen untuk memilih suatu produk.

Dengan pola dan gaya hidup masyrakat Indonesia yang bukan hanya mementingkan soal kualitas tetapi juga mementingkan aspek kehalalan, maka Maxim sebagai produsen Teflon piranti alat masak di Indonesia melihat celah peluang pasar tersebut sehingga melakukan sertifikasi kehalalan dalam produknya. Uniknya, walau Maksim tidak memproduksi barang pangan dan konsumtif namun Maksim melakukan terobosan dengan memberikan label halal untuk produk piranti masak Teflon. Sebagai produsen produk non konsumtif, Maxim menjadi pemimpin dan pionir produsen alat masak yang berani mensertifikasi produknya dengan label halal. Walaupun, label halal biasa diberikan kepada produksi barang konsumtif namun Maxim mengambil pembeda yakni sebagai piranti masak anti lengket halal pertama dan satu-satunya di dunia. Dengan pembeda dengan penggunaan label halal ini, Maxim memberikan komitmen dengan cara memberikan kenyamanan saat memasak kepada konsumen. Melalui Teflon berlabel halal, Maxim menawarkan keutungan kepada konsumennya yakni bukan saja menawarkan teknologi piranti anti lengket untuk memasak tetapi juga memberikan kepastian dan perlindungan dengan label halal, karena produk Maxim telah melalui serangkaian audit untuk memenuhi kriteria halal sehingga produk ini aman digunakan. Hal ini dibuktikan dengan teflon yang telah diverifikasi oleh para tenaga ahli LPPOM MUI, dengan bukti sertifikat halal dengan nomor sertifikat 00170067471213 yakni sejak 2013 (LPPOM MUI, 2018). Selain aspek halal, Maxim juga memberikan aspek thoyyib yakni memberikan kepastian rasa aman yang berarti aman untuk digunakan, tidak membahayakan kesehatan bagi konsumen Maxim.

Dengan penggunaan label halal dalam produk Maxim, masyarakat bukan saja melalukan pertimbangan sebelum melakukan pembelian selain aspek citra produk. Dengan trend positif bahwa angka penduduk Indonesia adalah penganut Islam secara mayoritas, maka sangat menguntungkan bagi Maxim dengan penggunaan label halal tersebut. Dengan kondisi tersebut, peneliti tertarik meneliti mengenai penggunaan label halal untuk memudahkan konsumen dalam memilih dan memtuskan dalam membeli barang yang bukan untuk dikonsumsi yakni peralatan memasak. Untuk mendukung penelitian ini, peneliti menggunakan beberapa penelitian terdahulu untuk mendukung penelitian yang dilakukan oleh peneliti. 


\section{SEGMEN Jurnal Manajemen dan Bisnis \\ Volume 17 No 2 Juli 2021 \\ p-ISSN: 0216-938X e-ISSN: 2684-8414}

Tengku Putri Lindung Bulan yang meneliti label halal memberikan hasil empiris dalam penelitiannya yakni bahwa label halal berpengaruh positif dan signifikan terhadap keputusan pembelian (Bulan \& Rizal, 2016), penelitian lainnya dilakukan oleh Mohamad Syahriar Sugandi yang focus meneliti penggunaan label halal untul produk non konsumtif yakni kulkas, dalam penelitiannya mendapatkan fakta empiris bahwa label halal mempengaruhi minat konsumen untuk membeli barang, Penelitian lainnya dilakukan oleh Ismail Fahmi Arrauf dalam penelitiannya membuktikan bahwa penggunaan label halal memberikan pengaruh terhadap keputusan pembelian dengan produk kosmetik (Fahmi Arrauf Nst, 2018). Sehingga, dari paparan penelitian terdahulu yang penulis paparkan maka novelty penelitian ini adalah penggunaan label halal untuk produk non konsumtif yakni perangkat masak Teflon Mastin dengan variable kualitas produk dan label halal yang memberikan pengaruh kepada keputusan konsumen.

Adapun tujuan penelitian ini adalah untuk melakukan riset pengaruh label halal terhadap produk non konsumtif yakni peralatan memasak Teflon. Sehingga, dengan penelitian ini hendak membuktikan bahwa bukan hanya vairabel kualitas merek yang hanya mempengaruhi keputusan pembelian namun penggunaan label halal dapat memberikan pengaruh terhadap keputusan pembelian. Dari tujuan penelitian ini maka dapat disimpulkan bahwa penelitian ini hendak melihat bahwa dalam pengambilan keputusan pembelian disesuaikan prefrensi konsumen yakni konsumen yang lebih senang memakai barang barang atau produk yang sesuai dengan syariat Islam yakni memenuhi kaidah kehalalan suatu produk.

\section{KAJIAN TEORI}

Dalam memproduksi suatu produk perlu adanya kepastian dengan adanya label halal. Dasar hukum pemberian label halal berasal dari perintah Allah yang tercermin dalam firmanNya di dalam Alquran. Sehingga, dengan adanya label halal merupakan suatu bentuk penjaminan yang diberikan kepada suatu produk sehingga produk tersebut memenuhi syarat kehalalan yang sesuai dengan Syariat Islam (Syafrida, 2016). Dengan kondisi demikian, maka label halal bukan saja dipandang sebagai bentuk mentaati aturan Syariat berdasarkan firman Allah dalam Alquran, tetapi dengan adanya label halal, menjadi suatu perlindungan konsumen khususnya untuk penganut agama Muslim di Indonesia (Faridah, 2019).

Negara dengan dasar hukumnya, juga memberikan perhatian terhadap perlindungan hak konsumen Muslim terhadap sebuah produk. Peraturan tersebut tertuang dalam Undang-Undang Nomor 33 Tahun 2014 yang mengatur mengenai ketersediaan produk halal dan haram oleh produsen (Halal, 2014). Dengan peraturan hukum tersebut, maka pelaku usaha harus mematuhi dan menyediakan produk-produk halal demi kepentingan masyarakat Muslim.Lebih lanjut, MUI dengan LPPOM mengatur pengajuan sertifikat label halal dengan HAS 23000. HAS 23000 yang mengatur persyaratan sertifikasi halal yang ditetapkan oleh LPPOM MUI untuk mendapatkan sertifikasi kehalalan sebuah produk. Persyaratan tersebut mengatur mengenai kriteria Sistem Jaminan Halal (SJH). 


\section{SEGMEN Jurnal Manajemen dan Bisnis \\ Volume 17 No 2 Juli 2021 \\ p-ISSN: 0216-938X e-ISSN: 2684-8414}

Terdapat 11 kriteria SJH yang dicakup dalam HAS 23000 (LPPOM MUI, 2021) yakni: (1) kebijakan halal, (2) tim manajemen halal, (3) pelatihan, (4) bahan, (5) fasilitas produksi, (6) produk, (7) prosedur tertulis aktivitas kritis, (8) kemampuan telusur, (9) audit internal, (10) penanganan produk yang tidak memenuhi kriteria, (11) kaji ulang manajemen Dengan adanya kriteria tersebut, memudahkan baik produsen maupun konsumen untuk mendapatkan produk halal. Lebih lanjut, dengan adanya label halal diharapkan akan dapat mempengaruhi keputusan konsumen dalam memutuskan menggunakan barang yang ada.

Pola konsumen yang membeli bukan hanya berdasarkan kualitas produk, tetapi juga kehalalan dalam sebuah produk membuat gaya hidup baru dimana produk produk yang memiliki label halal sangat dilirik dan menjadi pertimbangan konsumen utuk dapat di beli. Kualitas produk dapat didefinisikan sebagai setiap tindakan atau kegiatan yang dapat ditawarkan oleh suatu pihak kepada pihak lain, yang pada dasarnya tidak berwujud dan tidak mengakibatkan kepemilikan apapun (Nalendra et al., 2019).

Dengan definisi tersebut, maka kualitas produk dapat dilihat karakteristiknya menjadi (Buyung, 2016): (1) tangible, (2) reliability, responsiveness, (4) assurance, dan (5). Emphaty (Buyung, 2016) dan (Dinawan, 2010) juga menjelaskan bahwa keputusan pembelian adalah suatu keputusan berdasarkan tindakan dan pemikiran konsumen untuk memutuskan pembeliandengan melakukan pertimbangan sebagai berikut: (1) pemenuhan kebutuhan, (2) pemahaman kebutuhan, (3) proses mencari barang, (4) proses evaluasi, (5) pengambilan keputusan pembelian.

\section{HASIL DAN PEMBAHASAN}

Penelitian ini merupakan penelitian deskriptif kualitatif menggunkanan data primer (Nalendra, 2021), data dikumpulkan melalui survei kepada sejumlah responden yang merupakan pemakai produk Teflon Maxim sebanyak 120 orang dengan teknik purpose sampling (Sugiyono, 2016).

Teknik analisis data menggunakan regresi korelasi dengan melakukan pengujian hipotesis guna menemukan jawaban atas penelitian, perangkat lunak yang dipakai untuk olah data yaitu SPSS. Uji instrumen dilakukan dengan uji validitas dan reliabilitas. Uji Validitas berfungsi untuk menguji instrument yang digunakan menghasilkan pengukuan yang tepat dan cermat sedangkan uji reliabilitas digunakan untuk memastikan instrument yang dipakai dapat dipercaya, konsisten ketika digunakan dalam penelitian (Nalendra et al., 2019). Model penelitian seperti terlihat pada gambar 1.

Dimana $\mathrm{X}_{1}$ adalah label Halal, dan $\mathrm{X}_{2}$ adalah kualitas produk dan $\mathrm{Y}$ yakni keputusan pembelian. Hipotesis yang diajukan dalam penelitian ini yaitu:

$\mathrm{H}_{1}=$ terdapat pengaruh yang positif dan signifikan antara label halal terhadap keputusan pembelian

$\mathrm{H}_{2}=$ terdapat pengaruh yang positif dan signifikan antara kualitas produk terhadap keputusan pembelian.

$\mathrm{H} 3=$ terdapat pengaruh yang positif dan signifikan antara label halal dan kualitas produk secara bersama-sama terhadap variabel keputusan pembelian. 


\section{SEGMEN Jurnal Manajemen dan Bisnis \\ Volume 17 No 2 Juli 2021 \\ p-ISSN: 0216-938X e-ISSN: 2684-8414}

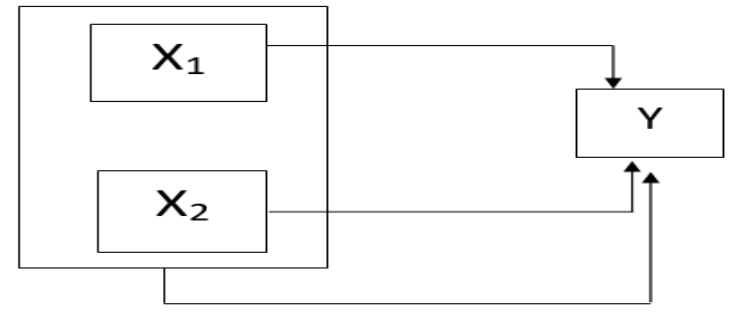

Gambar 1.

Model Penelitian

(Sumber: data primer diolah, 2020)

\section{Uji Validitas dan Uji Reliabilitas}

Uji instrumen terhadap butir pertanyaan untuk variabel $\mathrm{X}_{1}, \mathrm{X}_{2}$ dan $\mathrm{Y}$, yaitu dengan menguji tingkat validitas dan reliabilitas. Pada variable label halal $\left(\mathrm{X}_{1}\right)$ didapat hasil dari 29 butir yang pertanyaan dilakukan uji validitas ditemukan hasil yakni 14 butir dinyatakan valid. Sedangkan dalam pengujian reliabilitas instrumen didapat nilai koefisien alpha sebesar 0,869 . Untuk variabel lainnya yakni kualitas produk $\left(\mathrm{X}_{2}\right)$ setelah dilakukan uji validitas didapat hasil yakni dari 25 butir pertanyaan terdapat 9 butir yang dinyatakan valid. Untuk proses uji reliabilitas didapat hasil yakni pada variable nilai koefisien alpha sebear 0.734 sehingga dinyatakan reliabel. Pada variable keputusan pembelian (Y) peneliti melakukan uji instrument dengan uji validitas telah diujicobakan dengan jumlah sebanyak 23 butir menghasilkan valid sebanyak 10 butir yang tidak valid sebanyak 13. Setelah melakukan uji validitias, dilanjutkan uji reliabilitas serta mendapatkan butir yang reliable dengan hasilnya adalah koefisien alpha sebesar 0,680 dan dinyatakan reliabel.

\section{Uji Hipotesis}

Uji Hipotesis dilakukan guna mendapatkan jawaban atas sejumlah hipotesis yang diajukan. Rincian dari pengujian hipotesis sebagai berikut:

\section{1. pengaruh Label Halal terhadap Keputusan Pembelian}

Hasil perhitungan disajikan pada tabel 1 , dimana nilai nilai $\mathrm{F}$ hitung sebesar 14.1111 dengan nilai signifikan $<0,05$, sehingga dapat dikatakan bahwa label halal memiliki pengaruh yang positif dan signifikan terhadap keputusan pembelian

Hal ini juga sejalan dengan penelitian yang dilakukan oleh (Bulan \& Rizal, 2016) yang menyatakan bahw memang konsumen lebih prefer untuk membeli produk yang terdapat label halalnya.

Hasil penelitian juga membentuk persamaan regresi $\hat{\mathrm{Y}}=20,448+0,219 \mathrm{X}_{1}$ yang diinterpretasikan bahwa perubahan baik itu penuruan atau kenaikan satu satuan skor terhadap label halal $\left(\mathrm{X}_{1}\right)$ akan mempengaruhi kenaikan atau penurunan satu satuan skor pada keputusan pembelian (Y) sebesar 0,219 pada konstanta 20,448. Hasil perhitungan juga menunjukkan nilai korelasi yang disajikan pada table 2 antara variable label halal $\left(\mathrm{X}_{1}\right)$ dengan keputusan pembelian $(\mathrm{Y})$ sebesar 0,327. Dengan hasil perhitungan tersebut, maka hipotesis pertama dalam penelitian ini terpenuhi. 
Tabel 1

\begin{tabular}{lccc}
\multicolumn{4}{c}{ Hasil Perhitungan Regresi } \\
\hline \multicolumn{1}{c}{ Variabel } & $\begin{array}{c}\text { Unstandardized } \\
\text { Coefficient Beta }\end{array}$ & $\begin{array}{c}\mathrm{t} \\
\text { Hitung }\end{array}$ & Sig \\
\hline Constant & 20.488 & 7.947 & 0.000 \\
\hline Label Halal $\left(\mathrm{X}_{1}\right)$ & 0,219 & 3.756 & 0.000 \\
\hline $\mathrm{F}$ & 14,111 & & 0,050 \\
\hline Sumber: data primer diolah, 2020 & & &
\end{tabular}

Tabel 2

Korelasi Keputusan Pembelian (Y) dan Label Halal ( $\left.\mathrm{X}_{1}\right)$

\begin{tabular}{lccc}
\hline & Keputusan Pembelian (Y) & Label Halal $\left(\mathrm{X}_{1}\right)$ & Sig \\
\hline Keputusan Pembelian $(\mathrm{Y})$ & 1 & $0,327^{* *}$ & 0,000 \\
\hline Label Halal $\left(\mathrm{X}_{1}\right)$ & $0,327^{* *}$ & 1 & 0,000 \\
\hline Sig & 0,000 & 0,000 & \\
\hline Sumber: data primer diolah, 2020 & &
\end{tabular}

2. Pengaruh Kualitas Produk terhadap Keputusan Pembelian

Hasil perhitungan dapat dilihat pada tabel 3, dimana nilai $\mathrm{F}$ hitung sebesar 17,529 > F tabel dengan nilai signifikan $<0,05$, sehingga dapat dikatakan bahwa kualitas produk memiliki pengaruh yang positif dan signifikan terhadap keputusan pembelian

Menurut Fahmi Arrauf Nst (2018) dalam penelitian juga mengatakan hal yang sama bahwa konsumen akan membeli didasari oleh mutu atau kualitas barang yang dirasakannya baik.
Tabel 3 juga menggambarkan hubungan antara kualitas produk dan keputusan pembelian melalui persamaan regresi $\hat{\mathrm{Y}}=15,367+0,500 \mathrm{X}_{2}$ yang menunjukkan bahwa setiap perubahan kenaikan atau penurunan satu satuan skor kualitas produk $\left(\mathrm{X}_{2}\right)$ akan mempengaruhi kenaikan atau penurunan satu satuan skor pada variable $\mathrm{Y}$ yaitu keputusan pembelian (Y) sebesar 0,500 pada konstanta 15,367. Nilai korelasi dapat disajikan pada table 4, sebesar 0,360. Dengan hasil perhitungan tersebut, maka hipotesis kedua dalam penelitian ini terpenuhi.

Tabel 3

\begin{tabular}{lccc}
\multicolumn{4}{c}{ Hasil Perhitungan Regresi } \\
\hline \multicolumn{1}{c}{ Variabel } & $\begin{array}{c}\text { Unstandardized } \\
\text { Coefficient Beta }\end{array}$ & $\begin{array}{c}\mathrm{t} \\
\text { Hitung }\end{array}$ & Sig \\
\hline Constant & 15,367 & 4.368 & 0.000 \\
\hline Kualitas Produk $\left(\mathrm{X}_{2}\right)$ & 0,500 & 4.187 & 0.000 \\
\hline $\mathrm{F}$ & 17,529 & & 0,050 \\
\hline Sumber: data primer diolah, 2020 & & &
\end{tabular}


Tabel 4

Korelasi Keputusan Pembelian (Y) dan Kualitas Produk ( $\left.\mathbf{X}_{2}\right)$

\begin{tabular}{lccc}
\hline & Keputusan Pembelian $(\mathrm{Y})$ & Kualitas Produk $\left(\mathrm{X}_{2}\right)$ & $\mathrm{Sig}$ \\
\hline Keputusan Pembelian $(\mathrm{Y})$ & 1 & $0,360^{* *}$ & 0,000 \\
\hline Kualitas Produk $\left(\mathrm{X}_{2}\right)$ & $0,360^{* *}$ & 1 & 0,000 \\
\hline Sig & 0,000 & 0,000 & \\
\hline Sumber: data primer diolah, 2020 & &
\end{tabular}

\section{Pengaruh Label Halal dan Kualitas} Produk secara bersama-sama terhadap Keputusan Pembelian.

Hasil perhitungan secara simultan dapat dilihat pada tabel 5, dimana nilai $\mathrm{F}$ hitung sebesar $11.485>\mathrm{F}$ tabel dengan nilai signifikan $<0,05$, hal ini mencerminkan bahwa keputusan membeli (Y) dipengaruhi secara positif dan signifikan oleh label halal $\left(\mathrm{X}_{1}\right)$ dan kualitas produk $\left(\mathrm{X}_{2}\right)$ secara langsung atau simultan. Penelitian (Syafrida, 2016) dan (Faridah, 2019) juga mengindikasikan hal yang sama, namun tidak secara eksplisit mengatakan berapa besar pengaruhnya. Namun penelitian secara garis besar telah membuktikan bahwa pencantuman label halal dan peningkatan kualitas produk memang menjadi kunci utama agar konsumen mau dan berminat untuk membeli.

Tabel 5

Hasil Perhitungan Regresi

\begin{tabular}{lccc}
\hline \multicolumn{1}{c}{ Variabel } & $\begin{array}{c}\text { Unstandardized } \\
\text { Coefficient Beta }\end{array}$ & $\begin{array}{c}\mathrm{t} \\
\text { Hitung }\end{array}$ & Sig \\
\hline Constant & 13.037 & 3.602 & 0.000 \\
\hline Label Halal $\left(\mathrm{X}_{1}\right)$ & 0.139 & 2.206 & 0.000 \\
\hline Kualitas Produk $\left(\mathrm{X}_{2}\right)$ & 0.371 & 2.832 & \\
\hline $\mathrm{F}$ & 11,486 & & 0,050 \\
\hline Sumber: data primer diolah, 2020 & & &
\end{tabular}

Tabel 6

Korelasi Keputusan Pembelian (Y), Label Halal ( $\left.\mathbf{H}_{1}\right)$ dan Kualitas Produk $\left(\mathbf{X}_{2}\right)$

\begin{tabular}{lcccc}
\hline & $\begin{array}{l}\text { Keputusan } \\
\text { Pembelian }(\mathrm{Y})\end{array}$ & $\begin{array}{l}\text { Label } \\
\text { Halal }\left(\mathrm{X}_{1}\right)\end{array}$ & $\begin{array}{l}\text { Kualitas } \\
\text { Produk }\left(\mathrm{X}_{2}\right)\end{array}$ & Sig \\
\hline Keputusan Pembelian $(\mathrm{Y})$ & 1 & 0,327 & 0,360 & 0,000 \\
\hline Label Halal $\left(\mathrm{X}_{1}\right)$ & 0,327 & 1 & 0.444 & 0,000 \\
\hline Kualitas Produk $\left(\mathrm{X}_{2}\right)$ & 0,360 & 0.444 & 1 & 0,000 \\
\hline Sig & 0,000 & & 0,000 & \\
\hline Sumber: data primer diolah, 2020 & & &
\end{tabular}

Berdasarkan table 5, dijelaskan bahwa koefisien arah regresi b1 $=0,139$ dan $b=0,371$ dengan nilai konstanta (a) adalah 13,037 sehingga dapat persamaan regresi $\hat{Y}=13,037+0,139 \mathrm{X} 1+0,371$ $\mathrm{X} 2$. Ditemukan pula korelasi antara X1 dengan Y, dilakukan dengan uji Product Moment Correlation. Dari hasil 


\section{SEGMEN Jurnal Manajemen dan Bisnis \\ Volume 17 No 2 Juli 2021 \\ p-ISSN: 0216-938X e-ISSN: 2684-8414}

pengujian diperoleh koefisien korelasi $r$ $\mathrm{X}_{1}$ terhadap Y sebesar 0,327. Sedangkan korelasi antara $\mathrm{X}_{2}$ dengan $\mathrm{Y}$, dilakukan dengan uji Product Moment Correlation. Dari hasil pengujian diperoleh koefisien korelasi $r$ sebesar 0,360 sehingga dapat diinterpretasikan bahwa terjadi korelasi antara variabel $\mathrm{X}_{1}$ dan $\mathrm{X}_{2}$ dengan variabel $\mathrm{Y}$ adalah signifikan dengan demikian maka memenuhi hipotesis dalam penelitian ini.

\section{SIMPULAN}

Berdasarkan penelitian ini, maka dapat disimpulkan bahwa Konsumen selalin melihat kualitas merek tetapi juga melihat adanya label halal. Dari hasil analisa serta perhitungan yang ada, maka dapat disimpulkan bahwa terdapat pengaruh label halal dengan keputusan pembelian pada produk Teflon Maxim. Artinya bahwa konsumen dalam membeli sebuah produk bukan hanya melihat baik atau buruknya suatu merek namun juga melihat adanya label halal sebagai bahan pertimbangan untuk memutuskan membeli suatu produk.

Nilai 0,327 merupakan fakta empiris yang menunjukan bahwa adanya korelasi antara adanya label halal dengan keputusan pembelian yang bersifat positif dalam mempengaruhi keputusan pembelian. Konsumen membeli produk Teflon Maxim dengan pertimbangan adanya label halal. Selain itu, peneliti juga menemukan fakta empiris yakni nilai 0,360 yang didapat antara variable kualitas merek dengan keputusan pembelian. Dengan nilai tersebut, dapat disimpulkna bahwa selain adanya label halal, keputusan pembelian produk Teflon Maksim ditentukan dengan kualitas merek yang sudah baik. Fakta empiris lainnya adalah bahwa variable label halal, dan kualitas produk memberikan pengaruh bersama sama dalam keputusan pembelian. Penelitian ini juga memiliki keterbatasan sehingga masih perlu adanya penelitian lanjutan yang dapat memperbaharui riset yang ada.Dengan penelitian ini harapanya bahwa di masa mendatang akan ada penelitian lanjutan berkaitan dengan penggunaan label halal untuk produk produk non pangan dan konsumtif. Sehingga dapat memperkaya kazanah penelitian di bidang manajemen.

\section{DAFTAR PUSTAKA}

Bulan, T., \& Rizal, M. (2016). Pengaruh Labelisasi Halal terhadap Keputusan Pembelian Sosis di Kuala Simpang Kabupaten Aceh Tamiang. Jurnal Manajemen Dan Keuangan Unsam, 5(1), 431-439.

Buyung, S. (2016). Pengaruh Citra Merek,Kualitas Produk Dan Harga Terhadap Keputusan Pembelian Produk Semen Tiga Roda Di Toko Lico. Jurnal Berkala Ilmiah Efisiensi, 16(4), 376386.

Dinawan, M. R. (2010). Analisis FaktorFaktor yang Mempengaruhi Keputusan Pembelian (Studi kasus pada konsumen Yamaha Mio PT. Jurnal Sains Pemasaran Indonesia, IX(3), 335-369. Fahmi Arrauf Nst, I. (2018). Pengaruh Label Halal Terhadap Keputusan Pembelian Produk Kosmetik (Studi Kasus: Mahasiswi FEBI IAIN Langsa). 2-7. http://halalmuijatim.org/sertifikasi/tent ang-sertifikat-halal/.

Faridah, H. D. (2019). Halal certification in Indonesia; history, development, and implementation. Journal of Halal 


\section{SEGMEN Jurnal Manajemen dan Bisnis \\ Volume 17 No 2 Juli 2021 \\ p-ISSN: 0216-938X e-ISSN: 2684-8414}

Product and Research, 2(2), 68. https://doi.org/10.20473/jhpr.vol.2issue. 2.68-78

Halal, P. (2014). www.bphn.go.id. 1.

LPPOM MUI. (2018). Dengan Sertifikat Halal, Maxim Tembus Timur Tengah. 18-12-2018.

https://www.halalmui.org/mui14/main/ detail/dengan-sertifikat-halal-maximtembus-timur-tengah

LPPOM MUI. (2021). Kriteria Sistem Jaminan Halal dalam HAS23000. 21 MARET 2021.

https://www.halalmui.org/mui14/main/ page/kriteria-sistem-jaminan-halaldalam-has 23000

Lingkar, M. (2020). Pengaruh Pencantuman Label Halal Terhadap Minat Beli Produk Kulkas Merk ' Sharp .' Jurnal Komunikasi, 6(1), 44-55.

Nalendra, A. R. A. (2021). STATISTIKA SERI DASAR DENGAN SPSS. CV. MEDIA SAINS INDONESIA.

Nalendra, A. R. A., Winarno, S. H., Susanti, I. D., \& Latumahina, J. (2019). Pengaruh Kualitas Produk, Harga dan Citra Merek Produksi Tiongkok Terhadap Keputusan Pembelian (Studi Ksus HP Android Xiaomi). Jurnal Mitra Manajemen, 3(12), 1171-1181. http://e- jurnalmitramanajemen.com/index.php/ jmm/article/view/125/69

Review, W. P. (2021). Muslim Population by Country 2021. 2021. https://worldpopulationreview.com/co untries/indonesia-population

Sugiyono. (2016). Metode Penelitian Kuantitatif, Kualitatif dan $R \& D$. Alfabeta.

Syafrida Syafrida. (2016). Sertifikat Halal Pada Produk Makanan Dan Minuman Memberi Perlindungan Dan Kepastian Hukum Hak-Hak Konsumen Muslim. ADIL JURNAL HUKUM, 7(2). https://academicjournal.yarsi.ac.id/ind ex.php/Jurnal-ADIL/article/view/353 